\title{
Southern University Libraries in the Twentieth Century
}

$\mathrm{T}_{1}$ HE GOVERNOR ${ }^{1}$ has offered us a new look at the twentieth-century South. President Richards has asked me to make the application to university libraries. When I think of a region in terms of university libraries, I think first of library cooperation. Library cooperation is a natural among neighbors. I want to speak briefly, then, of the factors which influence university library cooperation in the South.

When a writer acknowledges a debt for the sources of his ideas, he uses a footnote. I wish to begin with a verbal footnote in large type. During the past two years I have had the opportunity to sit in on meetings of the Southeastern Interlibrary Research Facility, popularly known as SIRF. For those of you who may not know about SIRF, I should say simply that it is a cooperative library group composed of six libraries in Florida and Georgia, represented by university administrators, head librarians, and representatives of the Southern Regional Education Board, which is also a member and a very important one. SIRF has a full-time librarian executive secretary and an office at the Southern Regional Education Board headquarters in Atlanta.

I have listened carefully at the SIRF

${ }^{1}$ Governor Clements of Tennessee, an earlier speaker at the same session.

Mr. Lyle is director of libraries, Emory University. This paper was presented at the General Session, ALA Conference, Miami Beach, June 22, 1956. meetings. If it seems to those in the audience who have also attended these meetings that I have developed the sensitivity of a photographic plate, let me emphasize that these are my personal views-that I am not presuming to speak for SIRF-even though I owe much of what I have to say to my observations there.

One more prefatory note. Library cooperation in the South is not as remarkable as its press notices, but it has a record of solid accomplishment. It would be easy for me to stress the accomplishment, but I have a horror of repeating what is already thoroughly reported and recorded. The outsider, looking in. would immediately point to the distinguished career of Louis R. Wilson and his efforts in library cooperation, would hail the successful venture in interlibrary cooperation between Duke and Chapel Hill, the establishment of the Joint University Library in Nashville and the union catalog center at Nashville, the establishment of the Union Catalogue of the Atlanta-Athens Area as a part of the University Center program there, the comprehensive description of library resources in the area by Robert B. Downs, Richard B. Harwell and others, and most especially the cooperative efforts spearheaded by the Southeastern Library Association and its offers. I feel sure these accomplishments are well known to all of you. I am sure also that you and I will agree that these accomplishments have been truly outstanding. I am equally sure you do not 
wish me to take your time repeating the story once again. Rather, in developing the background on university library cooperation in the region, let me suggest three factors which affect cooperation and relate them to the specifics of what may be accomplished.

First, the central importance of national library cooperative effort cannot be over-emphasized. Important as the force of regionalism is, it should not lead us to secede from the United States. No single library lives in bibliographical isolation; neither can the region. For example, on the one hand, less than 50 per cent of the titles searched by readers in the Union Catalogue of the AtlantaAthens Area since September, 1955, were located in the area. Seventy-five per cent of Emory's interlibrary borrowings this year came from libraries outside the South. On the other hand, cooperation at the national level has done much to unite the resources of the world of books. Southern librarians team up with their colleagues in other parts of the country to establish a national pool of foreign newspapers on microfilm. Southern librarians join with librarians in the East, Middle West, and Far West in tapping the federal treasury to offset their fiscal limitations in promoting library extension services. Southern scholars benefit as much as their colleagues from Maine to Minnesota through the services of the National Union Catalog. Many other examples might be given, but it should be clear from these few illustrations why our first obligation as individual librarians and as state and regional library associations is to promote bibliographical organization and programs at the national level. They have proved worth while and much remains to be done.

In the second place, we recognize that the coordination of research collections must be identified with strong, healthy entities. Only two libraries in the South have as many as a million volumes and one of these is almost outside continental United States. Mere numbers is a crude measure of strength, but when the diversity of subject matter demanded by the range of university studies is taken into account, it is readily apparent that few southern university libraries have the collections necessary to support their present graduate and research programs. The lacks are not in peripheral areas; they may be characterized as an absence of the principal standard treatises, source editions, and periodicals in the basic disciplines, without which higher research is impracticable. In spite of recent gains, we have less to spend on our college and university libraries than any other region in the country. The South spends $\$ 309$ per thousand population for college and university libraries. The northeast and north central regions struggle along on $\$ 425$, while the far west has to be content with $\$ 560$. We feel that this deficiency must be made up. Cooperation will not make libraries strong if they are inadequate to begin with. It takes time, money, and great effort to build wisely selected research collections. We are not deluding ourselves into thinking that we can achieve greatness by drawing closer together a mass of mediocrity. Even though we may be able to draw a chart showing there is no overlapping in our library collections, the chart won't show the volumes we don't have, without which higher research will not be possible.

Parenthetically, I should like to add that because of the economies frequently identified with cooperation, there is real danger that administrators, trustees, and legislators may be misled into thinking that cooperation may make up for the deficiencies in our individual library book budgets. The force of this opinion does not arise in theory but from practical experience. I recall that shortly after a meeting of SIRF in Atlanta, 
there appeared an editorial in one of the metropolitan newspapers stating that through their cooperative efforts six libraries in Georgia and Florida expected to save as much as two million dollars in the next five years. No one at the SIRF meetings, as I recall it, particularly stressed the economies of cooperation, and no one, for certain, remotely suggested the idea of any such saving as this. Nevertheless the news was spread abroad, and inasmuch as the amount of the saving is only slightly less than the probable combined book budgets of the six institutions for the next five years, the reader of the editorial might readily surmise that if we cooperated just a little more vigorously the book budgets of the six libraries could be entirely liquidated.

In the third place, we recognize that the most effective and efficient method of coordinating resources is not open to us, at least not at the present. As we all know, university libraries could build stronger libraries cooperatively and more economically if there were a division of the field of collecting. Such a division necessarily depends upon the willingness on the part of scholars and university administrators to discourage the graduate offerings in a particular subject or subjects when a quality job is being done at some other institution in the region. This is the point where the professor's interest in cooperation becomes merely academic. As a matter of fact, I am inclined to think that the scholar who is interested in any kind of library cooperation is the exception rather than the rule. Talk to him about placing his departmental collection in the main library where the books will be more readily available to the university public as a whole and he reacts as though you were rubbing sandpaper - the double-zero number-on his stomach ulcer. Talk to him about substituting interlibrary loan for the purchase of an expensive journal file which he believes he or his students may conceivably use some day and you pump another pint of sulphuric acid into his system. And as Dr. Robert D. Leigh of Columbia has pointed out, "Few indeed are the administrators who accept the notion that any field of learning should be assigned permanently to a sister institution, along with the major responsibility for maintaining the library collections in that field."2 It is not the job of the librarian to reconcile these competitive views and aspirations of scholars and university administrators, but until the latter achieve a greater measure of success in allocating the areas of graduate work and research, the most direct and effective route to interlibrary cooperation is roadblocked.

These, then, are the three principal factors that must be taken into account when we plan the machinery of interlibrary cooperation in the South. Conversely, I feel that any plan of cooperation which contradicts or ignores these factors will fail in its purpose.

Now, as to the specifics of what may be accomplished in the immediate future.

In World War II it was found that the most effective method of advance was to press on where you are strong, rather than to reinforce where you are weak. We are strong and well established in our interlibrary lending practice. Not all faculty members have realized the significance of a free flow of interlibrary loans, nor reacted to its possibilities. The more the scholar realizes its advantages, the less prejudiced he will be about other forms of library cooperation. A material improvement in interlibrary loan service is possible without overstraining the library.

For a number of years in the southeast, and I expect it is true of other regions, there has been a kind of unwrit-

2"The Background of Interlibrary Cooperation," 
ten code in force among neighboring libraries which provides for a more liberal policy of interlibrary loan than the national code would seem to allow. Not all libraries adhere to the unwritten code partly because of a tiptoe caution on the part of the librarian or library committee, but chiefly, I suspect, because the borrowing library is hesitant about asking for material whose loan is discouraged by the national code. We have been raised, you know, to look upon interlibrary loans as a courtesy or favor one library renders to another. Perhaps at the regional level we should regard it as a duty to lend and not a favor to ask. The kind of lending restricted by the national code includes current fiction, current issues of periodicals, domestic in-print books, books for class use, rare books, a high percentage of the books basic for a thesis, a large number of titles at one time, and works difficult and expensive to pack. The statement covering the lending of microfilm is inadequate and there is no mention of microcards and microprint. Certain libraries in the southeast and in other areas are lending many types of material restricted by the national code and experiencing no difficulty in doing so. Therefore, it would seem likely that a revision of the code for regional purposes to incorporate the liberal lending policies which many libraries are now practicing would furnish a salutary stimulus to interlibrary lending in the region.

Secondly, we could profit greatly by the publication of regional union lists and guides to special collections and types of research materials where the job is not or cannot be done at the national level. To close the gap between the Union List of Serials and New Serials Titles, for example, by compiling and publishing a supplement to the former would be tremendously helpful in locating hundreds of journal files acquired by southern university libraries in the past seven years and for determining titles of journals not available anywhere in the South.

Another form of library cooperation that might be reinforced has largely gone unheralded. It consists of informal agreements among neighbor libraries to avoid needless duplication of expensive sets, the relocation of partial sets where it is mutually advantageous, and the occasional joint undertaking of an expensive purchase or microfilming job. One set of Adams Papers, or Early American Imprints, is sufficient for all users in the Atlanta-Athens area even though each set is held by a different library. This kind of cooperation goes on all the time; it does not depend upon formal organization reinforced by binding agreements or sweetened by a grant of foundation money. Its usefulness would be extended if the acquisition of these monumental research publications were promptly reported and the information distributed to the principal research libraries in the region.

Photoduplication services, imaginatively used, afford a powerful stimulus to library cooperation. The feasibility of a single agency in each state undertaking a newspaper microfilming program of its local newspapers has already been demonstrated in Florida, Louisiana, Alabama, Kentucky, and Georgia. In these states the state university library or the state historical agency has undertaken the task of filming local newspapers in the state which are not already available on film from the publisher or in some other library. Although the experiment is limited in scope, partly through want of funds and partly through the necessity of developing cooperative machinery in accordance with actual local requirements, it has already demonstrated its practicability and convinced those who are familiar with it that it is an

(Continued on page 422) 
without isolating them from those for related materials already in the catalog.

In the opinion of the library staff, the benefits of the project far outweigh the difficulties involved and the time and effort spent. The catalog is now more accurate and complete because some errors in cataloging, typing, and filing have been eliminated. Statistics of the number of cards withdrawn from the catalog were not kept, but the removal of cards for see also references, inverted titles, and unnecessary series did result in a slight reduction of the size of the catalog. The librarians believe that they learned much about the book collection represented by the cards in their particular section of the catalog. The reference librarian also says that she learned a great deal about cataloging and can better interpret the book collection from the catalog. She reports that she actually misses her daily stint of card catalog revision!

\section{Southern University Libraries in the Twentieth Century}

(Continued from page 389)

indispensable part of any program of interlibrary cooperation.

Finally, the university libraries of the South have felt the need for some broadly based organization in the region to serve (1) as a clearing house and discussion ground for cooperative projects and (2) to give direction, guidance, and support to those that are deemed sufficiently important. The genesis and spirit of this idea is to be found in SIRF, the Southeastern Interlibrary Research Facility. SIRF as now defined, however, is limited to library cooperation between university libraries in Georgia and Florida; if the regional aims of the Southern Regional Education Board are to be carried out, SIRF should become a genuinely regional library cooperative organization. This will come about, it seems to me, inevitably, but the immediate roadblock to expanding SIRF is the cost to the participating libraries of maintaining a strong central organization to give thrust and momentum to the ideas for cooperative action generated by the librarians of the region. If the Southern Regional Education Board could see its way clear to maintaining and financing a library department, particularly in the next few years when southern university libraries are straining every dollar to strengthen their collections and services, it would greatly speed up the machinery of interlibrary cooperation and enable us to serve scholarship better in the Southeast. I am aware that the proposal for establishing a library department of the Southern Regional Education Board is one which is asking the board to undertake an additional financial responsibility of some magnitude. On the other hand, each library will be contributing substantially from its own funds and staff time in assisting the department to carry out specific cooperative bibliographic projects. The extension I suggest would provide additional services beyond what could be provided by a library association staffed with purely voluntary assistance. It is the kind of extension which I feel sure the Southern Regional Education Board, of which our principal speaker is an important member, would not refuse if it were satisfied that it was for the general welfare of education in the South; moreover, this would enable it to extend some portion of the benefits of their public funds to the great multitude of scholars in the South who do not have the neighboring backstop of great repositories such as exist in the Harvard and Yale University libraries. 